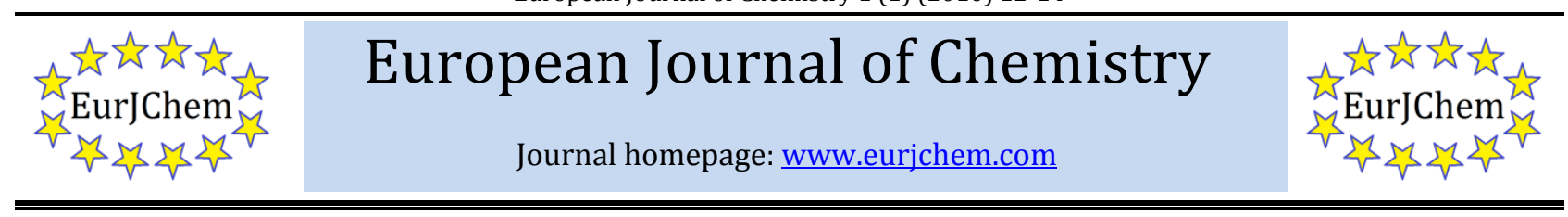

\title{
Biotechnological treatment of effluent from the combined enzymatic- ultrasound scouring of raw wool
}

\author{
Dancho Yordanov*, Rositza Betcheva and Lubov Yotova \\ a Department of Textile Chemistry, University of Chemical Technology and Metallurgy, Sofia, BU-1000, Bulgaria.
}

${ }^{*}$ Corresponding author at: Department of Textile Chemistry, University of Chemical Technology and Metallurgy, Sofia, BU-1000, Bulgaria. Tel.: +359.88793709391; fax: +359.287.22544. E-mail address: danchoyordanov@gmail.com (D. Yordanov).

\section{ARTICLE INFORMATION}

Received: 15 February 2010

Received in revised form: 12 March 2010

Accepted: 16 March 2010

Online: 31 March 2010

\section{KEYWORDS}

Wool scouring effluent

Aerobic treatment

Anaerobic treatment

Clean technology

Activated-sludge

Enzyme

\begin{abstract}
New eco-labels for textile products and demands to wastewater discharges are forcing wool scouring processes to reuse wastewater and to search for more efficient and environmental friendly methods of processing. This challenge has prompted intensive research in new advanced treatment technologies. Due to the high level of detergent usage, the most widely used treatment of wool scouring effluent (WSE) is anaerobic. As the pressure to use more environmentally acceptable treatment methods increases there is the need to study alternative, biologically efficient treatment systems for WSE. This work aims at studying the influence of the combined enzymatic-ultrasound scouring of raw wool fibers on the effectiveness of the anaerobic treatment of effluents from this processing. Experiments carried out combined enzyme and ultrasound scouring of wool followed by treatment of effluents obtained. Aerobic and anaerobic treatments of these effluents were performed using a special laboratory reactor. Chemical oxygen demand (COD) and biochemical oxygen demand (BOD) of effluents from different scouring processes were defined. The results of this study indicate that the anaerobic biological and chemical treatments of WSE treated by combined enzymatic-ultrasound scouring is a promising alternative technology from the point of view of reducing the wastewater pollution and the effective cleaning of effluents coming out from this process.
\end{abstract}

\section{Introduction}

The classical process of raw wool washing is accompanied by high pollution of wastewaters containing contaminators of organic and non-organic origin (fats, proteins and detergents). As a result of this the chemical oxygen demand (COD) reaches $100000 \mathrm{mg} / \mathrm{L}$ and the biochemical oxygen demand (BOD) varies from 20000 to 40000 (mg/L) [1], which seriously complicates the process of purification. It is well known that the existing methods for purification of effluents coming from washing of raw wool are not effective enough. There are two alternatives for increasing the level of purification. The first one is to decrease the level of pollution, through implementation of new ecologically pure technologies, which do not apply detergents and assure partial oxidizing of the pollutants during the process of washing. The second one is the implementation of modified biotechnological processing that provides an opportunity of obtaining a higher level of purification of effluents. Series of modifications of anaerobic processes for biological purification of wastewaters with various nature and composure are widely used. They are performed by means of bioreactors that have different hydrodynamic conditions to execute the processes [2]. An example of such a successful modification is the rotating anaerobic biocontactor spinning disc reactor with fixed biomass (SDR).

Available information shows that the research in this area is focused on searching technological solutions for rotating anaerobic biocontactor with fixed biomass [3-6] as well as decreasing or total replacement of washing detergents that are used in the process of washing of raw wool with ecologically clean enzyme compounds [7-10].

The study aims to present the influence of combined enzymatic and ultrasonic treatments of raw wool on the effectiveness of the anaerobic treatment of this process effluent.

\section{Experimental}

\subsection{Materials and treatments}

The enzymes used in this study were the commercials proteases Bioprot Multi, Bioprot Gentle and Neoprotease-L, supplied by Biocon S.A. Bulgarian Merino raw wool (quality 64 and fibre diameter about 22-25 $\mu \mathrm{m}$ ) was used for the experiment. They were treated at the following conditions: Quantity of wool, 75 g.; Volume of bath, $3000 \mathrm{~mL}$; $\mathrm{pH}=7.5$ phosphate buffer; $0.25 \%(\mathrm{w} / \mathrm{v})$ enzyme. The wool scouring was performed in an originally designed laboratory equipment that combines the scouring bath and ultrasonic generator with a frequency of emission $45 \mathrm{kHz}$.

\subsection{Biochemical Oxygen Demand (BOD) and Chemical oxygen Demand (COD)}

The detection of BOD and COD of wool scouring liquor was performed in accordance with the standard method: 5210 Biochemical Oxygen Demand (BOD) [12]; 5220 Chemical Oxygen Demand (COD) [13]. 


\subsection{Total suspended solids (TSS)}

Portion of the TSS retained on a filter with a specified pore size was measured after being dried at a specific temperature of $105{ }^{\circ} \mathrm{C}$. The filter used for determination of TSS was the Whatman glass fiber filter, with a normal pore size of about $1.58 \mu \mathrm{m}$.

\subsection{Experimental set-up}

The 3D plan view of the experimental setup is shown on Figure 1. The anaerobic spinning disc reactor (AnSDR) has a capacity of $3 \mathrm{~cm}^{3}$ with a working volume of $1.8 \mathrm{~cm}^{3}$. The AnSDR technology uses a thermopile stage. The temperature was $55 \pm 0.5{ }^{\circ} \mathrm{C}$. The gasholder and the primary setting tank had a capacity of $2.7 \mathrm{~cm}^{3}$ and $3.5 \mathrm{~cm}^{3}$, respectively.

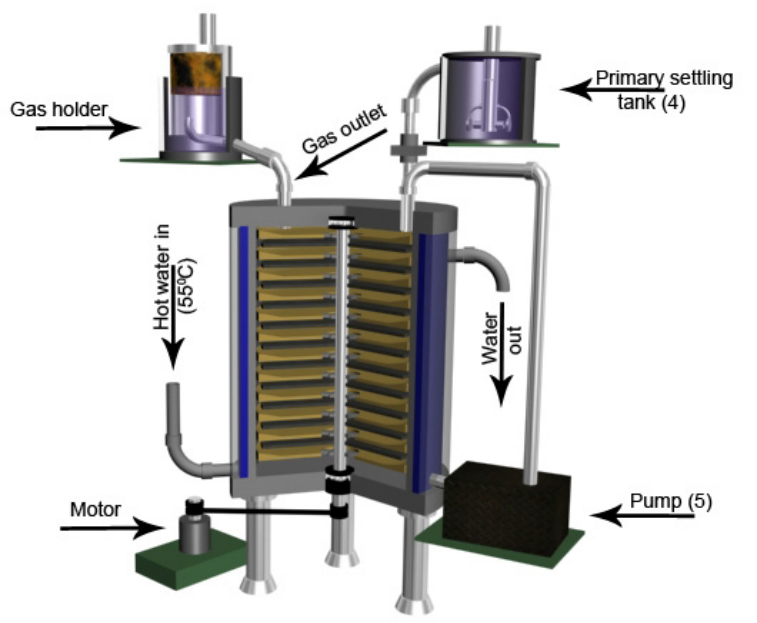

Figure 1. 3D visualization of the used laboratory installation.

Several characteristics of the anaerobic process as well as the existing models for defining the parameters of anaerobic bio-discs were taken into account in order to determine the dimensions of the bio-discs and to build the reactor [11]. Contemporary mathematical models based on the kinetics of the bacterial growth and considering the mass-exchange processes occurring on the bio-discs have been taken into consideration as well. After certain transformations of the existing model several mathematical equations were adopted to calculate the diameters of bioreactor discs. It was found out that if the internal diameter of the bioreactor is do $60 \mathrm{~mm}$ diameters of the bio-discs as well as their forms have to be different. In our case disc (1) has an even surface and a diameter of $\mathrm{d}_{1} 50 \mathrm{~mm}$, while disc (2) has a diameter of $\mathrm{d}_{2}$ $58 \mathrm{~mm}$, representing a cone-like surface with an inclination of (gradient) $33^{\circ}$. Both discs are shown in Figure 2.

The principle of function of (SDR) is shown in Figure 3. According to the presented scheme the polluted water gets into the primary settling tank, where the water insoluble pollutants are deposited into the anaerobic bioreactor. The wastewater on disc (1) is transferred by centrifugal force to the outer part of the disc. Due to the difference in the diameters, water falls onto disc (2) and by gravity falls to the center of the cone disc and passes through specially placed holes on to disc (3). Thus the treated water passes through the surface of the bio-discs reaching the pump (5) as shown in Figure 1 where the water is transferred back to the bioreactor (the cycle is repeated over and over again). Activated sludge (AS) has been taken from Sofia city purification station of wastewater (in Kubratovo village). AS was placed into the bioreactor for a period of 75 days, and each day it was supplied with biogenic elements and after the $30^{\text {th }}$ day it was fed with acetate. Every 72 hours an anaerobically treated wastewater sample has been taken for characterization $(\mathrm{pH}, \mathrm{COD}, \mathrm{BOD}$ and total suspended solids (TSS) was measurements).

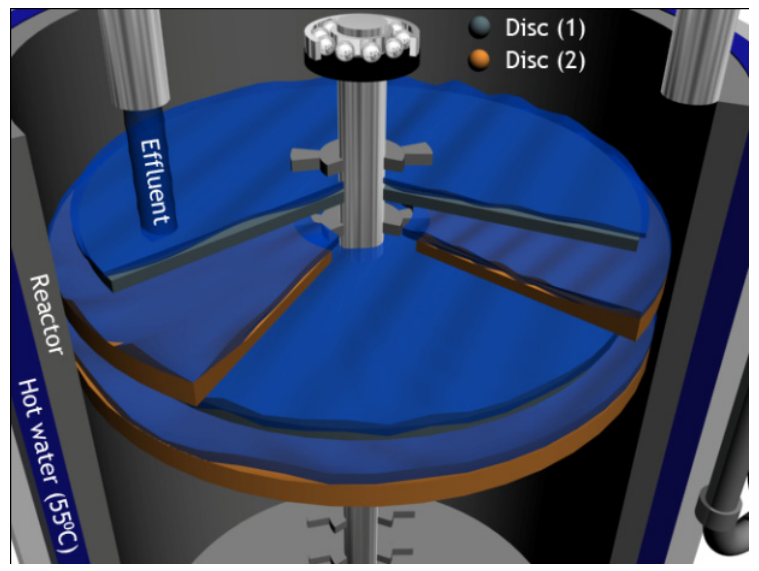

Figure 2. 3D visualization of discs 1 and 2

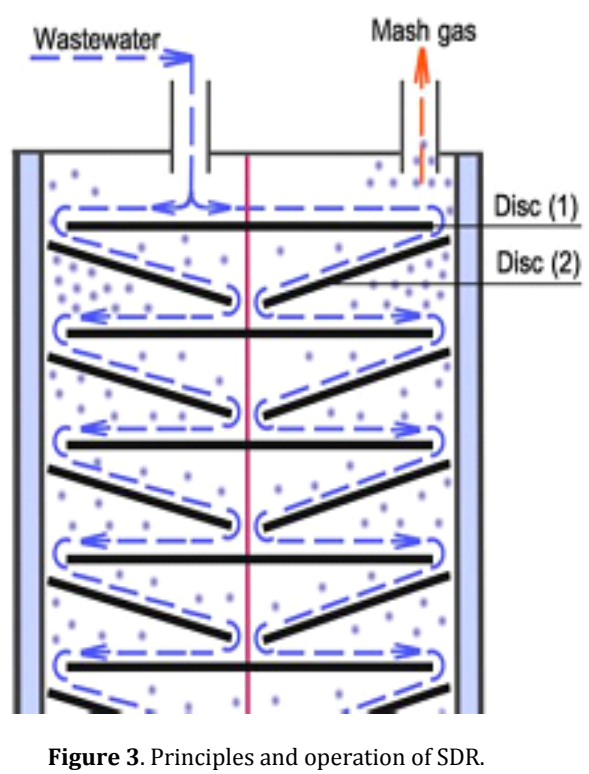

\section{Results and Discussion}

Results reflecting $\mathrm{pH}$ changes of anaerobically treated wastewaters can be seen in Table 1. Water, after the combined enzymatic-ultrasound wool scouring process is neutral, but after completing the anaerobic treatment it is alkaline. The alkalinity of the treated water has constant $\mathrm{pH}$ which is between 7.9 and 8.2 for all experiments with different enzymes for scouring and with different number of purification cycles. TSS values show a very high reduction even after only 1 cycle of purification. Impurities on the raw wool vary a lot in terms of their composition and quantity. This is a reason for the differences in $\mathrm{pH}$ and TSS of input water (scouring effluents). Bearing in mind the relative change of TSS before and after the anaerobic treatment applied in the presented study, the average value of the purification degree is in the range $70-80 \%$. This average value remains the same independent of the number of anaerobic treatment cycles applied (from 1 to 4 ) or enzymes used for scouring. Logically it could be supposed that a single cycle of 72 hours anaerobic treatment could be enough for an acceptable purification of studied effluents.

Measured values of COD and BOD are illustrated in Figure 4 and 5 . It can be seen that the decrease of COD of effluents 
Table 1. Total suspended solids (TSS) and pH at input and output after 72 hours treatment in anaerobic environment of wastewater under combined (enzymeultrasonic) processing of raw wool from: Neoprotease-L, Bioprot Multi and Bioprot General.

\begin{tabular}{|c|c|c|c|c|c|c|}
\hline \multirow{2}{*}{ Enzyme } & \multirow{2}{*}{ Number of purification cycles } & \multicolumn{3}{|c|}{ Total Suspended Solids } & \multicolumn{2}{|c|}{ pH } \\
\hline & & in $\mathbf{~ m g} / \mathbf{L}$ & out mg/L & Purification degree $\%(w / w)$ & in & out \\
\hline \multirow{4}{*}{ Neoprotease L } & 1 & 241 & 48 & 80.08 & 7.1 & 8.1 \\
\hline & 2 & 185 & 60 & 67.57 & 6.8 & 8.2 \\
\hline & 3 & 167 & 41 & 75.45 & 7.2 & 8.1 \\
\hline & 4 & 152 & 35 & 76.97 & 7.1 & 8.0 \\
\hline \multirow{3}{*}{ Bioprot Multi } & 1 & 187 & 42 & 77.54 & 6.7 & 7.9 \\
\hline & 2 & 162 & 38 & 76.54 & 6.9 & 7.9 \\
\hline & 3 & 198 & 52 & 73.74 & 7.2 & 8.2 \\
\hline \multirow{3}{*}{ Bioprot Gentle } & 1 & 215 & 67 & 68.84 & 7.1 & 8.0 \\
\hline & 2 & 196 & 45 & 77.04 & 7.0 & 7.9 \\
\hline & 3 & 231 & 63 & 72.73 & 6.9 & 8.1 \\
\hline
\end{tabular}

containing different enzymes at their output compared to their input is about $96-98 \%$. The decrease of BOD is also at the same high level of $96-98 \%$ after 72 hour treatment. The constructive solutions, applied for building this anaerobic reactor could be considered as a possible reason for the measured high change which could be connected with a highly effective purification. A possible explanation for this result could be the additional separation of the total water volume to smaller sections by biodiscs that leads to a better stabilization and control of the anaerobic process in the bioreactor. Another positive factor for the process acceleration is the possible action of centrifugal force generated by the spinning disc reactor (SDR) which assists the formation of more effective contact between the pollutant and the microorganisms enhancing their hydrolysis.

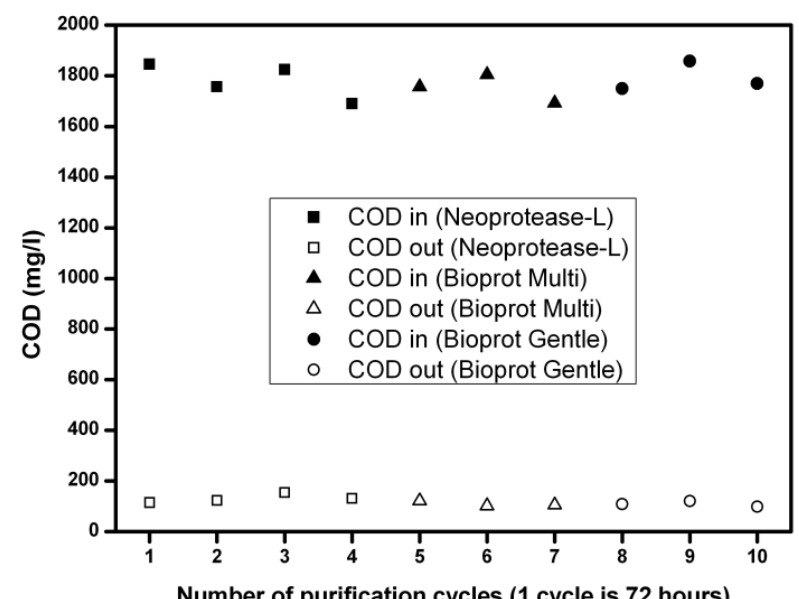

Figure 4. Chemical Oxygen Demand (COD), open symbol ( $\square-$ Neoproteases-L, $\Delta$-Bioprot Multi, o-Bioprot Gentle) - COD-in, closed symbol (a-NeoproteasesL, • - Bioprot Multi, $\mathbf{\Delta}$-Bioprot Gentle) - COD-out after 72 hours treatment

Experimental results for COD and BOD after the treatment applied in the presented study are: COD between 1700-1800 $\mathrm{mg} / \mathrm{L}$ and BOD $750-900 \mathrm{mg} / \mathrm{L}$. (e.g. the ratio BOD/COD 0.5). These values remain almost constant and obviously they do not depend on the type of enzyme used. The same is valid for the number of purification cycles applied and could be one more proof that 72 hours anaerobic treatment in our bioreactor would be enough for a sufficient purification of studied effluents. There is data showing that COD and BOD values for the conventional detergent washing of wool are $100000 \mathrm{mg} / \mathrm{L}$ and between $20000-40000 \mathrm{mg} / \mathrm{L}$, respectively. (e.g. BOD/COD $>>0.5$ ) [1]. Therefore, the logical conclusion from the ratio of COD/BOD $>>0.5$ is that the effluents containing detergents need a combination of several purification methods e.g. physical, physical-chemical or chemical methods, while an appropriate anaerobic treatment would be enough for the purification of effluents from enzymatic-ultrasound scouring of raw wool [11].

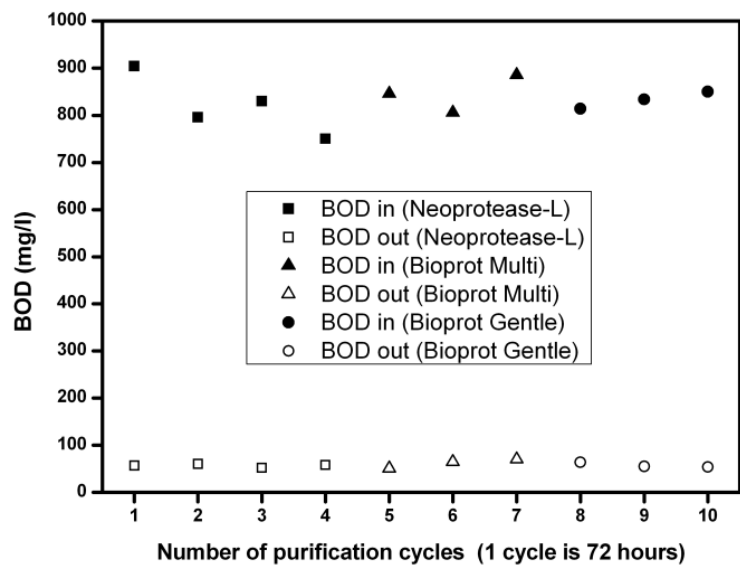

Figure 5. Biochemical Oxygen Demand (BOD), open symbol ( $\square-N e o p r o t e a s e s-L$, $\Delta$-Bioprot Multi, o-Bioprot Gentle) - BOD-in, closed symbol ( $-N$-Neoproteases-L, - - Bioprot Multi, $\Delta$-Bioprot Gentle) - BOD-out after 72 hours treatment.

\section{Conclusion}

Effluents from enzymatic-ultrasound scouring of raw wool posses relatively low level of COD and BOD. Purification of these effluents can be successfully performed with anaerobic treatment. Laboratory equipment with an original construction can purify protease-ultrasound raw wool washing wastewaters up to $98 \%$ of their COD and BOD values after 72 hours of anaerobic treatment.

\section{References}

[1]. Norman, P. I.; Seddon, R. J. Soc. Dyers Colour. 1991, 107, 215-218.

[2]. Sachs, J.; Meyer, P.; Rkehauer, P. Water Research 2003, 37, 973-982.

[3]. Oxley, P.; Brechtelsbauer, C.; Ricard, F.; Lewis, N.; Ramshaw, C. Ind. Eng. Chem. Res. 2000, 39(7), 2175-2182.

[4]. Brechtelsbauer, C.; Lewis, N.; Oxley, P.; Ricard, F. Org. Proc. Res. Dev. 2001, 5(1), 65-68.

[5]. Stankiewicz, A.; Moulijn, J. A. Ind. Eng. Chem. Res. 2002, 41(8), 19201924.

[6]. Vicevic, M.; Boodhoo, K.; Scott, K. Chem. Eng. J. 2007, 133, 43-57.

[7]. Silvaa, C. J. S. M.; Prabaharana, M.; Gubitzb, G.; Cavaco-Pauloa, A. Enzyme Microb. Tech. 2005, 36, 917-922.

[8]. Silvaa, C. J. S. M.; Prabaharana, M.; Gubitzb, G.; Cavaco-Pauloa, A Enzyme Micro. Tech. 2006, 39, 634-640.

[9]. Silvaa, C. J. S. M.; Guebitz, G.; Cavaco-Paulo, A. J. Chem. Tech. \& Biotech. 2006, 81(1), 8-16.

[10]. Schroeder, M.; Schweitzer, M; Lenting, H. B. M.; Guebitz, G. M. Biocatalysis biotransfor. 2004, 22, 299-305.

[11]. Tchobanoglous, G.; Burton, F. L.; Stensel, H. D. Metcalf \& Eddy Fourth edition. 2002.

[12]. 5210 B. 5-Day BOD Test. Approved by Standard Methods Committee, 1997.

http://www.norweco.com/html/lab/test methods/5210bfp.htm.

[13]. 5220 B. Open Reflux Method. Approved by Standard Methods Committee, 1997.

http://www.norweco.com/html/lab/test methods/5220bfp.htm. 